\title{
Dependency of Polyelectrolyte Complex Stoichiometry on the Order of Addition. 1. Effect of Salt Concentration during Streaming Current Titrations with Strong Poly-acid and Poly-base
}

\author{
Junhua Chen, John A. Heitmann, and Martin A. Hubbe*
}

Department of Wood and Paper Science, North Carolina State University, P. O. Box 8005, Raleigh, NC 27695-8005, USA

* Corresponding author. Tel.: +1-919-513-3022; fax: +1-919-515-6302. E-mail address: m_hubbe@ncsu.edu (M.A. Hubbe).

\section{Abstract}

Titrations were carried out between solutions of a strong poly-acid (polyvinylsulfate, potassium salt) and a strong poly-base (polydiallyldimethylammonium chloride) over a range of salt concentrations.

Streaming current analysis of the titration endpoints appeared to show increasing deviations from 1:1 stoichiometry of complexation with increased salt. The results depended on the direction of the titration, such that a stoichiometric excess of the titrant (second additive) was required to achieve a streaming current reading of zero. These symmetrical results, depending on the order of addition, were obtained despite the fact that the plastic surfaces of the streaming current device had a slight negative charge and differing adsorption tendencies for the two kinds of polymer. A qualitative model of molecular events, based on non-equilibrium entrapment of non-complexed polymer segments was found to be inconsistent with results of tests carried out over a range of initial polymer concentration. Results were better described by a qualitative model involving formation of polyelectrolyte complexes (PECs) in solution, in which nearstoichiometric core complexes are stabilized by an excess of the second additive 
on their surface. Implications of the latter model were compared with the results of turbidimetric tests, aqueous contact angles on polymer-treated plastic surfaces, and microelectrophoresis of PECs. Results of this study have consequences for interpretation of polyelectrolyte titrations, as well as for industrial operations that involve the mixing of oppositely charged polyelectrolytes.

\section{Keywords: ELECTROKINETICS, STREAMING CURRENT, POLYELECTROLYTE COMPLEXATION, TITRATIONS, STOICHIOMETRY}

\section{Introduction}

\subsection{Stoichiometry and the streaming current test}

The stoichiometry of interactions between water-soluble poly-acids and poly-bases has implications in such fields as wastewater treatment [1-2], papermaking [3-5], and analytical chemistry [6-8]. Though much relevant work suggests a tendency for 1:1 stoichiometry of polyelectrolyte interactions [9-14], some recent publications have identified conditions leading to systematic deviations from $1: 1$ stoichiometry $[8,10,13,15-22]$. Such deviations are expected to affect both the efficiency of polyelectrolyte usage in various industrial processes and also the accuracy of certain online and manual analytical tests that are used for process control. The present work was motivated by some unexpected results obtained during the course of streaming current (SC) 
titrations [22]. Preliminary tests showed that SC titrations carried out in the presence of salts depended on the order of addition of two polyelectrolyte solutions.

In recent years operators of paper machines have placed increasing reliance on streaming current (SC) titrations to control and optimize addition rates of polyelectrolyte additives. A previous article considered factors affecting the accuracy of such titrations, especially in the presence of low to moderate levels of monomeric salts [22]. Salt levels were found to affect the stoichiometry of polyelectrolyte titration results. These issues are increasingly important to paper technologists, due to increased rates of water reuse and consequent enrichment of ion concentrations.

Though fuller descriptions are given elsewhere [22-27], the SC test procedure can be stated briefly as follows. The wetted parts of the device include a plastic piston loosely fitted within a dead-ended plastic cylinder. A reciprocal motion of the piston within the cylinder causes an aqueous sample placed in the annulus to flow back and forth across the plastic surfaces. If the plastic surfaces bear a net charge, usually due to adsorption of colloidal material from the sample, then the fluid motion causes net movement of counter-ions in the diffuse double layer adjacent to the charged surfaces. This motion of ions is detected as a current by means of a pair of electrodes and suitable electronics, which also rectify and smooth the signal $[23,27]$. A common industrial test involves gradual addition of a polyelectrolyte solution to the sample [28-29]. The 
titration endpoint usually is identified with the point at which the signal equals zero.

Figure 1 provides an example of output from a SC titration, based on previously unpublished data. As noted in the earlier publication [22], an increasing level of sodium chloride produced three kinds of effects on the titration results, of which the second item is the main focus of the present work:

1. The absolute magnitudes of the initial signals were reduced. This is consistent with the known effect of salt on zeta potential values $[5,27,30]$, and in particular on streaming current signals [22-23,31-32].

2. The amount of titrant corresponding to zero streaming current tended to increase with increasing salt. In the earlier publication [22], all of the titrations were in the same direction. The initial solution always consisted of a polyacid (an anionic polyelectrolyte), and the titrant was always the high-charge linear cationic polymer.

3. At electrical conductivity levels higher than 2000 to $3550 \mu \mathrm{S} / \mathrm{cm}$ the endpoints became difficult or impossible to detect. The low end of this range corresponds to low charge density polyelectrolytes. Contributing factors to making SC measurements difficult at high salt levels were considered in the earlier publication [22].

<<FIGURE ONE NEAR HERE >> 


\subsection{Theoretical Background}

Previous investigators have advanced ideas to explain why or why not to expect a one-to-one pairing of charged groups in the formation of complexes between oppositely charged polyelectrolytes in solution. Two explanations of stoichiometric behavior are the so-called "ladder" and the "scrambled egg" models of polyelectrolyte complexation [33]. The ladder model assumes that the two polyelectrolytes have sufficient flexibility and suitable charge densities that they can zip together in a cooperative fashion $[3,12]$. An adaptation of the ladder model appears to be successful in explaining behavior of certain PECs formed from a "host" polyelectrolyte and a "guest" polyelectrolytes of much lower molecular mass $[16,34]$. However, when carrying out titrations or other complexation reactions between polyelectrolytes both having relatively high molecular mass it may not be reasonable to assume that the polyelectrolyte chains can untangle themselves and line up as highly regular "ladders." Thus, a "scrambled egg" model is expected to be a better description under the limiting conditions of high molecular mass, concentration, and/or flow where the rate of irreversible collisions between macromolecules is high relative to their rate of conformational adjustment [35].

The driving force for formation of polyelectrolyte complexation has been described in terms of either (a) attraction of oppositely charged groups $[3,16,34,37,39]$, or (b) an increase in entropy when polyelectrolyte complexation results in release of counter-ions $[3,9,33]$. These two explanations can be seen 
as complementary descriptions of the same phenomena. Though entropy considerations alone would lead us to expect irregular structures (possibly with incomplete pairing of charged groups), it is clear that electrostatic effects will tend to drive the system to rearrange itself so that as high a fraction as possible of the charged groups on the respective polyelectrolytes are paired up with their opposites. While it is clear that such rearrangement ought to yield 1:1 stoichiometry in the case of linear polyelectrolytes of similar charge density, previous studies have demonstrated 1:1 stoichiometry over a wide range of charge densities and charge density ratios, especially when the work is carried out in the absence of added low-mass ions, i.e. salts [9-14].

The present experimental work was limited to strong, linear, high-mass polyelectrolytes of high charge density. These conditions were selected to avoid certain known complications, as follows. First it has been shown that stable nonstoichiometric complexes can exist in solution in cases where the two polyelectrolytes differ strongly in molecular mass [3,16,36-37]. Other factors tending to produce non-stoichiometric polyelectrolyte interactions include sharply contrasting charge densities [17] and branched molecular structures [38-39].

\subsection{Hypothetical qualitative models}

Two idealized, qualitative models will be considered here in anticipation of experimental results to be shown later. Each of these models attempts to explain why titrations between a strong, linear, high-mass poly-acid and a corresponding poly-base ought to depend on the order of addition. In each case we are 
interested in the relative amounts of charged groups in the two polyelectrolytes that are present in the mixture when the titration has been carried out to a streaming current endpoint of zero. Though the idealized models are intended to cover two of the most likely explanations for non-stoichiometric titration results, there is no claim that every possible explanation has been considered. Also, the two models may not be mutually exclusive.

Figure 2 illustrates a "segment entrapment" model. This model emphasizes initial collisions, relatively early in a titration, when each titrant macro-ion is likely to be surrounded by poly-ions of opposite charge. The word "titrant" here refers to whichever of the poly-ions is gradually added to a solution of the oppositely charged polyelectrolyte. For the sake of this model it is assumed that complexation begins at the periphery of a titrant molecule, forming a layer of complexed units surrounding the central portion of the titrant molecule. It is further assumed that non-complexed segments of the titrant molecule become isolated and protected within the complexed layer. As suggested by Michaels et al. [9], a tightly coiled conformation, possibly due to the presence of salt, is expected to make some ionic groups inaccessible for reaction. Under conditions where the segment entrapment model is valid, the model implies deviations from 1:1 stoichiometry. Specifically, the model predicts that titrant will appear "inefficient" in terms the amount needed to fully titrate the sample. It should be noted that the segment-entrapment model is similar in concept, but different in detail from a model proposed by Stamberg et al. for the encapsulation of polyelectrolyte solutions [see 34]. 
Though the segment entrapment model remains to be proven, possible theoretical justifications can be given. The model requires, first of all, that rates of molecular collisions be fast relative to the rates of molecular conformations, factors that can be estimated based on concentrations, molecule sizes, and conditions of flow [35]. A second requirement of the model is that complexation is an essentially irreversible process. It must be reasonable to assume that the polyelectrolytes can remain "stuck" in the kind of non-equilibrium situation envisioned in Fig. 2. Evidence of such irreversibility has been observed in some other aspects of high-mass polyelectrolyte behavior, including adsorption onto oppositely charged surfaces [41] and formation of polymer bridges [35,42,43].

\section{<<FIGURES TWO AND THREE SOMEWHERE NEAR HERE>>}

Figure 3 illustrates a "surface excess" model to be evaluated as a second idealized explanation for non-stoichiometric endpoints of streaming current titrations. Here it is assumed that 1:1 stoichiometry of complexation prevails during the titration, even in the core regions of each polyelectrolyte. However, the resulting complexes are assumed to be charge-stabilized by whichever of the polyelectrolytes happens to be in excess at different parts of the titration. At the titration endpoint, detected by the streaming current method, it is assumed that tails and loops of the second added polymer (the titrant) extend outward from the surfaces of complexes that remain suspended in the solution $[37,44-46]$. 
To justify consideration of the surface excess model, it is proposed that the titrant continues to adsorb onto the surfaces of PECs after the point where a 1:1 stoichiometric endpoint might be expected. Such continued adsorption beyond the point of neutralization is consistent with recent studies of polyelectrolyte adsorption onto oppositely charged surfaces [47-51] or multilayers formed by successive dipping of a solid support surface into polyelectrolyte solutions of opposite charge nature [51-53].

Implications of the two competing models just described are similar in many respects, but there are some key differences. Both models agree with respect to the following qualitative predictions for interactions between linear, high-charge polyelectrolytes of similar molecular mass: (a) more titrant should be required to reach an endpoint, compared to 1:1 stoichiometry; (b) the effects ought to be approximately symmetrical, depending on which of two polyelectrolytes is used as the titrant; and (c) deviations from 1:1 stoichiometry ought to increase with increasing electrical conductivity due to less extended average molecular conformations of the individual poly-ions before they interact [54-55]. On the one hand, a denser conformation is expected to make titrant molecules easier to surround and entrap. Alternatively, denser molecular conformations should allow higher amounts of titrant molecules to be present in a stabilizing layer of a charge-stabilized complex. The latter explanation has been used by others to explain why intermediate levels of salt often increase adsorbed amounts of polyelectrolytes onto surfaces of opposite charge [56-57]. 
The two idealized models suggest contrasting behavior in certain other respects: (a) the segment entrapment model, which assumes that rates of collisions affect the interaction, ought to depend on the concentrations of both polyelectrolytes during the titration; and (b) the surface-excess model of chargestabilized polyelectrolyte complexes implies that at the streaming current endpoint at moderately high salt concentrations it should be possible to measure zeta potentials of such complexes that match the charge of the titrant.

\section{Experimental}

\subsection{Materials}

Experiments were conducted in solutions prepared from deionized water, to which different levels of salt were added. Table 1 shows the series of electrolyte additions and electrical conductivities that were used throughout the study.

$<<$ TABLE 1 NEAR HERE >>

Table 2 lists the polyelectrolytes used in this work. All were homopolymers with essentially $100 \%$ charged monomeric groups. The abbreviation PVSK stands for the potassium salt of poly-(vinylsulfonic acid). PVSK was prepared fresh from a master batch of dry powder (Aldrich), and the 
solutions were completely used within 2 months. The abbreviation poly-

DADMAC stands for poly-(diallyldimethylammonium chloride). Poly-DADMAC having a nominal molecular mass of 400-500 kiloDaltons was used in most experiments, except for turbidity tests reported in Tables 5 . The polyelectrolytes were used without further purification.

$<$ <TABLE TWO NEAR HERE >>

\subsection{Procedures}

Charge titration test: In order to be able to rule out device-specific effects, to different streaming current devices were used for polyelectrolyte titrations. Results of tests involving an ECA2000P (Chemtrac Systems, Inc.) are shown in Figs. 1 and 7 . Issues concerning the use of this instrument under conditions of increasing salt concentration were considered in an earlier publication [22]. Results of tests involving a PCD 03 pH (Mütek Analytic) are shown in Figs. 4-6 and 8-9. In all cases the polyelectrolyte samples were diluted with desired aqueous salt solutions to desired concentrations, then oppositely charged titrant was used to titrate to a zero signal at the end point. Titrant was added manually in the case of the ECA2000P, with approximately one minute of equilibration time after each addition. Titrant was added automatically in the case of the PCD 03 $\mathrm{pH}$, using the default settings of a Mütek PCD-T auto-titrator. 
Calibration of the PVSK titrant was carried out before each set of tests. The calibration was based on a streaming current endpoint in the absence of added monomeric electrolytes. The maximum length of time between recalibrations was 7 days.

Turbidity test: Aliquots of $20 \mathrm{ml}$ solutions with various conductivities were used as background electrolyte. The salt levels and conductivities are listed in Table 1. One ml of $0.001 \mathrm{~N}$ poly-DADMAC or 0.0008 to $0.0009 \mathrm{~N}$ PVSK was added in the preparation of each initial cationic and anionic solution, then the oppositely charged polyelectrolyte was used to titrate it. Titrant was added in $0.1 \mathrm{ml}$ steps in the presence of gentle stirring, followed by turbidity analysis with a DRT-15CD Turbidimeter from HF scientific, Inc. Poly-DADMAC samples of differing molecular mass were compared in this series of tests to find out whether the observed stoichiometry effects were limited to a narrow range of conditions or whether the effects have broad applicability.

In preparation for zeta potential tests (see next), further turbidity tests were carried out as follows. Replicate samples were prepared, in sets of 7, by adding $100 \mathrm{ml}$ of either deionized water or a selected salt solution. To each beaker, $5.0 \mathrm{ml}$ of $0.001 \mathrm{~N}$ poly-DADMAC (400-500k Dalton) was added, during gentle agitation, followed by $5.5 \mathrm{ml}$ of PVSK having an approximate strength of $0.0008 \mathrm{~N}$. Then, an additional $0.10,0.15,0.20,0.25,0.30,0.35$, or $0.40 \mathrm{ml}$ of PVSK was added to successive beakers. Turbidity and zeta potential values were determined after $20 \mathrm{~min} ., 5 \mathrm{hr}$. , and $24 \mathrm{hr}$. 
Electrophoresis test: Micro-electrophoresis experiments were included in the work due to the surprising nature of the streaming current titration results. The idea was to obtain a broad range of supporting data, based on independent tests, by which to judge the merits of the qualitative models described earlier. In order to estimate the zeta potential of polyelectrolyte complexes, electrophoretic mobility was measured with a Charge Analyzer Two (SKS Assoc.) Suspensions of pre-formed polyelectrolyte complexes, taken from the turbidity experiments, were added to the charge analyzer to measure the zeta potential.

Contact angle test: Contact angle measurements on polytetrafluoroethylene (PTFE) tape samples were used to sense effects attributable to polymer adsorption. PTFE tape samples were dipped into solutions containing $1.0 \mathrm{ml}$ of either poly-DADMAC or PVSK, plus $100 \mathrm{ml}$ of various conductivity solutions. After 30 minutes the tapes were withdrawn and solution was removed as much as possible by shaking, before measurement of the contact angle. The liquid used in the contact angle measurements was deionized water (about $0.04 \mathrm{ml})$.

\section{Results And Discussion}

\subsection{Streaming Current Titrations - Order of Addition}

Titrations were carried out between poly-(diallyldimethylammonium chloride) (poly-DADMAC) and the potassium salt of poly-(vinylsulfate) (PVSK) in 
deionized water, in the presence of hardness $\left(100 \mathrm{ppm} \mathrm{CaCl}_{2}\right)$, or in hard water (also $100 \mathrm{ppm}$ ) to which different amounts of $\mathrm{NaCl}$ had been added. In the first case to be considered, the initial solution consisted of poly-DADMAC at a concentration of $47.6 \mu \mathrm{eq} / \mathrm{L}$ after dilution, and the titrant consisted of about 0.0008-0.0009N PVSK. The PVSK solution was recalibrated before each set of titrations because of its limited stability. As shown in Fig. 4, the amount of titrant required in order to reach the endpoint of zero streaming current increased with increasing salt addition. Water hardness caused the volume of titrant required to reach the endpoint to increase by a factor of about $5 \%$ relative to titrations carried out in deionized water. The presence of $100 \mathrm{ppm}$ or $0.1 \% \mathrm{NaCl}$ concentration, in addition to the hardness ions, caused the endpoints to be shifted by about $12 \%$ to $16 \%$, respectively, compared to deionized water. The light- and dark-shaded histogram bars represent replicate experiments.

\section{<<FIGURES 4 AND 5 NEAR HERE>>}

To allow for more convenient comparison, results of the form shown in Fig. 4 were converted to a "+/-" format, following a convention used by others [37]. In this article the ratio always is expressed with the amount of titrant (second additive) in the numerator. The value of $+/-$ or $-/+$ can be taken as the stoichiometric ratio of titrant polymer groups to initially present polymer groups at the streaming current endpoint of the titration. Results shown in Fig. 5 correspond to a different set of titrations involving initial addition of poly- 
DADMAC having a concentration, after dilution, of $6.0 \mu \mathrm{eq} / \mathrm{L}$. Once again, addition of salt tended to increase the relative amount of titrant corresponding to zero output of the streaming current meter. While the results shown in Figs. 4 and 5 appear similar in nature to endpoint shifts reported earlier [22], it is worth noting that these new results involved the opposite direction of titration.

To confirm the earlier results, Fig. 6 shows additional results of tests in which the poly-anion (PVSK) was the initial solution and in which the poly-cation (poly-DADMAC) was the titrant. Again, increasing conductivity tended to make the titrant appear less effective in reaching the endpoint.

<<FIGURES SIX AND SEVEN NEAR HERE>>

Further confirmation of the effect was obtained with different brand of streaming current detector (see Experimental). The direction of titration corresponds to Fig. 5. As shown in Fig. 7 the same shift to higher $-/+$ values at the streaming current endpoint were evident with increasing electrical conductivity up to about $1000 \mu \mathrm{S} / \mathrm{cm}$. Above that point the $+/$ - values declined again. Possible reasons for unreliable SC output at very high conductivity were reviewed elsewhere [22].

\subsection{Baseline Tests of Streaming Current Output}


Before judging the appropriateness of either of the idealized qualitative models described earlier it is worth considering the results of some baseline tests. The first area of concern was a possible influence of the initial apparent charge of the plastic surfaces within the sensing areas of a streaming current apparatus. Though the poly-tetrafluoroethylene and other hard plastics used in fabrication of streaming current devices are usually described as "uncharged" and oleophilic, experience suggests that these surfaces develop a negative surface charge when exposed to water [23-24,31-32].

Figure 8 shows the results of tests carried out in the absence of any polyelectrolytes, but with the same saline solutions used in the other examples that have been shown. These results confirm the apparent negative character of the plastic surfaces of the streaming current device, as sensed by the apparatus in the absence of polyelectrolytes. The results also show a simple diminution in signal with increasing ionic strength, as shown by others $[5,30]$. Similar tests carried out over a range of $\mathrm{pH}$ values were consistent with the presence of anionic groups on the plastic surfaces being the main contribution to the apparent charge.

\section{<<FIGURES EIGHT AND NINE NEAR HERE>>}

Though the SC signal values shown in Fig. 8 appear relatively large, that does not imply that a large amount of cationic polymer was needed to reach a titration endpoint of zero. Figure 9 shows the results of a series of "titrations" 
starting with a cleaned apparatus and samples consisting of deionized water and various salt additions as outlined earlier. Within a conductivity range from near 0 up to $3550 \mu \mathrm{S} / \mathrm{cm}$, the amount of polyDADMAC needed to reach zero SC signal was 0.02 to $0.05 \mu \mathrm{eq}$, which amounts to $2-5 \%$ relative to the starting amount of polymer used during tests such as that shown in Fig. 4. Increasing amounts of titrant required to reach the zero $\mathrm{SC}$ endpoint at yet higher conductivity are consistent with a suppression of adsorption of the poly-DADMAC, as discussed previously [22]. At the highest conductivity levels tested the apparent deviations can be expected due to the decreased magnitudes of the signals and sensing limitations of the devices [22].

Figure 10 shows results of two series of tests in which SC signals were evaluated in the presence of single solutions of polyelectrolytes with different levels of monovalent ions. Results of tests carried out in the presence of PVSK (lower curve) were similar in their basic trend to those obtained in the absence of polyelectrolytes, except that the absolute magnitudes were approximately twice as large. This difference is consistent with adsorption of at least some of the PVSK onto the plastic surfaces. However, the present results do not provide sufficient information to demonstrate complete coverage of the plastic surfaces by the anionic polyelectrolyte. 
The upper curve in Fig. 10, corresponding to saline solutions of polyDADMAC, shows a maximum in positive signal within a conductivity range between 2 and about $1000 \mu \mathrm{S} / \mathrm{cm}$. Though the reason for this maximum has not been determined in this study, the trend appears consistent with known effects of salt levels on adsorbed amounts of cationic polymers onto negative surfaces in solution [56-58]. Such studies often show maxima in adsorbed amounts at intermediate salt levels, followed by partial or complete suppression of adsorption at the highest levels of salt considered by the investigators.

To summarize the baseline tests, the plastic probe surfaces behaved as if they had a weakly negative surface charge. The amounts of cationic polyelectrolyte to neutralize the charges of the bare surfaces of the apparatus, in the absence of anionic polyelectrolyte, were too small to account for the observed shifts in apparent stoichiometry of the complexation interactions, as sensed by the streaming current tests.

\subsection{Contact angle tests related to baseline conditions}

Results of contact angle tests are listed in Tables 3 and 4 . The measurements before adsorption represents blank experiments in which the poly-tetrafluoroethylene (PTFE) tape was dipped into salt solution without polymer added. This tape was considered similar to the surfaces used in the probe construction. The contact angle of PTFE samples that were never dipped 
in any solution was $116.4 \pm 1.8$ degree. Ranges show plus or minus one standard deviation from the mean. It should be noted that within each row of data the PTFE tape samples were obtained from the same roll. Differences in "before adsorption" values between the first two rows of Table 3 , and the remaining rows of Tables 3 and 4 can be attributed to a switch to a fresh roll of PTFE tape.

$<<$ TABLE 3 NEAR HERE >>

As shown in Table 3, contact angle differences between the conditions of before and after adsorption were apparent only at relatively low conductivities. This is consistent with an ability of the cationic polymer to adsorb at low conductivity onto the PTFE tapes, but not at high salt levels. PTFE has a negatively charged surface, whereas poly-DADMAC is cationic. Poly-DADMAC is hydrophilic, and PTFE is hydrophobic. It follows that the contact angle of PTFE will be decreased if poly-DADMAC is adsorbed. High conductivity is expected to repress the adsorption tendency [56-58].

<<TABLE FOUR NEAR HERE>>

In the case of PVSK the difference of the contact angle was not as large as in the case of poly-DADMAC. That is expected because PVSK carries a 
negative charge, reducing its tendency to adsorb onto the negative surface of the PTFE.

The present results also are consistent with previous tests with adsorption of chromo-poly-DADMAC onto PTFE powder [22]. Chromo-poly-DADMAC had been provided to us by Tanaka [21] as a copolymer with a bright red chromophoric group to render it highly visible. A PTFE surface appeared red after it exposure chromo-poly-DADMAC in low to medium conductivity solutions. In contrast, no red color could be seen after exposure of the PTFE to high conductivity solutions that contained chromo-poly-DADMAC.

\subsection{Tests at different polyelectrolyte concentrations in the initial solution}

Figure 11 shows the results of tests carried out with different amounts of PVSK added to the initial solution at low conductivity. All of these tests were carried out in the presence of $100 \mathrm{ppm} \mathrm{CaCl}_{2}$ and no $\mathrm{NaCl}$ (conductivity $=280$ $\mu S / \mathrm{cm})$. In each case the concentration of poly-DADMAC in the mixture, at the zero SC endpoint, was plotted relative to the initial concentration of PVSK. The plotted line is based on a linear regression of the data. The slope was equal to 0.964 and the coefficient of determination $\left(R^{2}\right)$ had a value of over 0.9990 . This indicates that the ratio of polyelectrolytes at the streaming current endpoint was independent of the concentration, over the range considered. Further tests were carried out with the identical conditions, but with the opposite direction of titration. Again, the slope was equal to 0.964 and the $R^{2}$ value also was 0.9987 . 
<<FIGURES 11 and 12 NEAR HERE>>

Figure 12 shows corresponding results at a high salt concentration (100 ppm $\mathrm{CaCl}_{2}$ and $1 \% \mathrm{NaCl}$ ) in the case of poly-DADMAC solutions of differing concentration that were titrated with PVSK. Once again, the regression line through the origin $\left(R^{2}=0.95\right)$ showed no significant dependency of the ratio of polyelectrolytes on the concentration of the starting solution. Note, however, that the slope of the regression line was 1.25 , reflecting the deviation from stoichiometry at high salt levels, as already discussed.

The lack of concentration-dependency in Fig. 12 at high conductivity appears to conflict with the segment-entrapment model outlined earlier in this article. In other words, if the non-stoichiometric endpoints had been due to polyelectrolytes becoming "stuck" in non-equilibrium situations, then one would expect such effects to become more prominent with increasing concentrations. This was not observed.

Elementary calculations of collision rates in gently stirred solutions [35], when applied to the polymer types and concentrations used in the present work, suggest collision half-lives within the range of 0.2 to 5 seconds over the concentration range of 5 to $150 \mu \mathrm{eq} / \mathrm{L}$ of the polyelectrolytes. Values assumed for these calculations included polymer radii of $50 \mathrm{~nm}$, a temperature of $25^{\circ} \mathrm{C}$, a shear rate of $100 \mathrm{~s}^{-1}$, and molecular mass near to 200,000 Daltons. The corresponding calculations for Brownian collisions, disregarding flow, yielded 
collision half-lives in the range of 0.7 to 20 seconds over the same concentration range. In comparison, it has been suggested that the conformation time of a polyelectrolyte of several hundred thousand $\mathrm{g} / \mathrm{mole}$ may be of the order of magnitude of 1 second [35]. Based on these estimates one would expect to see a dependency of the endpoint ratio on concentration, if in fact the process were dominated by kinetic factors related to collisions, as in the case of the segment entrapment model.

\subsection{Results of turbidity tests}

Turbidity tests were used in the manner of earlier investigators $[36,45]$ to detect the onset of precipitation of polyelectrolyte complexes during titrations carried out as already described. Representative results are shown in Figs. 1316 for cases in which the default poly-DADMAC of intermediate mass was used as the initial solution. Figure 13 shows results corresponding to low to moderate levels of monomeric electrolytes. The turbidity values under these conditions remained very low, almost up to the point of charge-equivalence between the poly-DADMAC and the PVSK titrant. Thereafter, the turbidity rapidly increased and remained high with further increases in the amount of PVSK.

One way to explain the results in Fig. 13 is to envision that nascent complexes, formed well before the equivalence point, have sufficient net positive charge so that coagulation is inhibited by electrostatic repulsion. Near the equivalence point the repulsion falls rapidly, so that particles grow large enough 
to scatter light effectively. The lack of further change in turbidity, upon further addition of titrant beyond the endpoint in Fig. 13, suggests that the buildup of polyelectrolyte complex particles big enough to scatter light is not easily reversible.

\section{<<FIGURES 13 and 14 NEAR HERE>>}

A subtle aspect in Fig. 13 requires further explanation. There were many individual experiments, such as this one, in which turbidity failed to show an anticipated increase in the absence of added salts $\left(\mathrm{CaCl}_{2}\right.$ and $\left.\mathrm{NaCl}\right)$. Subsequent tests showed that it was possible to observe strong increases in turbidity, even in the absence of salts, only if the titration was carried out very slowly in the vicinity of the equivalence point. Such results suggest the existence of a very narrow coagulation domain at very low ionic strength. In other words, it was possible to skip quickly past the point where coagulation could occur and restabilize the nascent complex particles in an oppositely charged form too small to scatter light effectively.

Figure 14 shows a much broader coagulation range in the corresponding titration carried out at the highest level of salt considered (100 ppm CaCl 2 and $1 \% \mathrm{NaCl}$ ). This observation is consistent with coagulation of charged, suspended particles [5]. A gradual dip in the turbidity at the highest levels of titrant addition, beyond the equivalence point, is tentatively attributed to a weakening of complexation interactions at high salt levels [59-60]. According to 
that interpretation, the system would be expected to be more reversible and capable of becoming restabilized upon addition of excess titrant, in comparison with similar tests at relatively low levels of monomeric electrolytes.

Figure 15 shows related results in which the anionic polymer (PVSK) constituted the initial solution, and poly-DADMAC served as the titrant. Once again, turbidity values tended to remain very low until the equivalence point was approached. Thereafter, the turbidities either remained high or gradually declined with further increases in titrant amount. Again, it was possible to skip past the point of destabilization when titrations were carried out at the normal rate in the absence of added salts. The fact that the results in Fig. 13 and 15 are very similar is consistent with the symmetry shown earlier in Figs. 4 through 7 for streaming current titrations carried out in opposite directions.

<<FIGURES 15 and 16 NEAR HERE>>

Figure 16 shows corresponding results in the case of the highest salt level considered $\left(100 \mathrm{ppm} \mathrm{CaCl}_{2}\right.$ and $\left.1 \% \mathrm{NaCl}\right)$. Here the appearance of a maximum in turbidity, near to the equivalence point, is most pronounced.

Table 5 summarizes results of similar turbidimetric titrations carried out under the same range of salt conditions, but with the initial polymer consisting of poly-DADMAC samples having three different average molecular masses. The values of $-/+$ at the point of most rapid turbidity rise were determined from graphs by observing the abscissa values of the rising curves at one-half of the turbidity 
maxima. As shown, effects due to increasing salt concentration were apparent for all three cases, not just with the intermediate poly-DADMAC mass represented in Figs. 13-14. However at each salt level the point of most rapid turbidity rise depended upon molecular mass of the poly-DADMAC. In the case of the lowest-mass poly-DADMAC, addition of PVSK titrant resulted in colloidal instability already at relatively low values of the titration ratio (-/+), especially at the two highest levels of salt. In the case of the highest-mass poly-DADMAC, the same titration conditions did not result in colloidal instability until the PVSK titrant addition was much closer to the stoichiometric point. While the present work does not provide enough evidence to reach a firm conclusion, such behavior is consistent with an increasing ability of the larger poly-DADMAC molecules to act as "hosts" for the smaller PVSK "guests" in colloidally stable complexes [16,36].

< TABLE FIVE NEAR HERE>>

No consistent trends relative to molecular mass were observed when a parallel set of tests was carried out with poly-DADMAC samples of differing molecular mass used to titrate PVSK solutions, at various salt concentrations. This lack of dependency on molecular mass tends to cast doubt on the "entrapment" model in Fig. 2. Molecular mass would be expected to affect whether a titrant molecule can untangle itself rapidly enough to avoid isolation of non-complexed segments. 


\subsection{Results of microelectrophoresis tests}

Results of microelectrophoresis tests indicated that during titrations the suspended matter in the colloidal phase reached zero zeta potential long before achievement of a zero streaming current endpoint. In these tests PVSK was added as a titrant to solutions of poly-DADMAC. Tests in the absence of $\mathrm{CaCl}_{2}$ or $\mathrm{NaCl}$ yielded positive zeta potential values in the range of $+20 \mathrm{mV}$ to $+26 \mathrm{mV}$ when the mixture became turbid at ratios $(-/+)$ of PVSK ionic groups to polyDADMAC groups between 0.93 and 0.95 . Zero mobility was observed in the suspended matter upon further addition of PVSK when the ratio $(-/+)$ had reached 0.978. The SC endpoint was at 1.000 (see Experimental).

Visual and turbidimetric observations from the tests just described were consistent with a mechanism of charge stabilization of the polyelectrolyte complex particles in suspension. The particle size after $24 \mathrm{hrs}$ aggregation was

generally larger than that after $5 \mathrm{hrs}$, consistent with ongoing coagulation. A drop in turbidity was noted in the case of those mixtures for which the measured zeta potential was near zero. Such behavior is consistent with the disappearance of charge repulsion under those conditions, allowing particles to approach each other, stick together efficiently, form large aggregates, and settle [61].

A series of additional tests were carried out with PVSK gradually added to poly-DADMAC solutions at different salt levels, but always with the same ratio of anionic to cationic polyelectrolyte groups. It was found that polyelectrolyte additions at a ratio $(-/+)$ equal to 0.962 yielded negative zeta potentials of the 
polyelectrolyte complexes for all samples that contained at least $100 \mathrm{ppm}$ of $\mathrm{NaCl}$ in addition to the standard $100 \mathrm{ppm}$ of hardness. However, Fig. 5 shows that the corresponding streaming current endpoint was not reached until the ratio $(-/+)$ was either about 1.08 or higher, depending on the level of salt. This observation again supports the existence at the SC endpoint of charge-stabilized complexes of the type illustrated in Fig. 3. In other words, the "surface excess" model of polyelectrolyte complexes in colloidal suspension appeared to be most consistent with the present observations regarding the stoichiometry of streaming current titrations.

\section{Conclusions}

1. In the presence of $\mathrm{CaCl}_{2}$ and $\mathrm{NaCl}$ the endpoint of titrations between strong, linear, high-charge polyelectrolyte solutions, using a streaming current endpoint, depended on which of the two solutions was used as the titrant. Deviations from 1:1 stoichiometry increased with increasing $\mathrm{NaCl}$ concentration.

2. Results were consistent with the existence, during the titrations, of chargestabilized polyelectrolyte complexes in which charge-stability involves an excess of one of the polyelectrolytes at the surface of each particle. These particles continue to take up titrant even after their zeta potential has been reversed. 
3. The present study helps to explain some apparent shifts in polyelectrolyte complexation stoichiometry in earlier studies involving streaming current endpoints. The results also reinforce earlier recommendations to minimize errors by diluting high-conductivity samples with known ratios of distilled water to bring the electrical conductivity below about $1000 \mu \mathrm{S} / \mathrm{cm}[22]$.

\section{Acknowledgements}

The authors gratefully acknowledge the support of start-up funds from North Carolina State University and the people of North Carolina for the reported work.

\section{References}

[1] M. M. Ghosh, C. D. Cox, T. M. Prakash, Polyelectrolyte selection for water treatment, J. Amer. Water Works Assoc 77 (3) (1985) 67-73.

[2] M. M. Abu-Orf, S. K. Dentel, Automatic control of polymer dose using the streaming current detector, Water Environ. Res. 70 (5) (1998) 1005-1008.

[3] S. H. Tse, The Effects of lonic Spacing and Degree of Polymerization on the Stoichiometry of Polyelectrolyte Interactions in Dilute Aqueous Solutions, Ph.D. Diss., Inst. Paper Chem., Appleton, WI, 1979.

[4] G. Ström, P. Stenius, Formation of Complexes, Colloids, and Precipitates in Aqueous Mixtures of Lignin Sulfonate and Some Cationic Polymers, Colloids Surf. 2 (4) (1981) 357-371.

[5] T. Lindström, Electrokinetics in the Paper Industry, in Paper Chemistry, J. C. Roberts, Ed., Blackie, London, 1991, 25-43.

[6] H. Terayama, Method of Colloid Titration - A New Titration between Polymer lons, J. Polymer Sci. 8 (1952) 243-253.

[7] D. Horn, Optical Secondary Beam Procedure for Determination of Polyelectrolytes in Water and for Measurements of Polymer Adsorption on Surfaces, Prog. Colloid Polymer Sci. 65 (1978) 251-264.

[8] S. K. Kam, J. Gregory, Charge Determination of Synthetic Cationic Polyelectrolytes by Colloid Titration, Colloids Surf. A 159 (1) (1999) 165179. 
[9] A. S. Michaels, L. Mir, N. S. Schneider, A Conductometric Study of Polycation-Polyanion Reactions in Dilute Aqueous Solution, J. Phys. Chem. 69 (5) (1965) 1447-1455.

[10] R. B. Cundall, J. B. Lawton, D. Murray, Polyelectrolyte Complexes. 1. The Effect of $\mathrm{pH}$ and lonic Strength on the Stoichiometry of Model Polycation Polyanion Complexes, Makromol. Chem. 180 (1979) 2913-2922.

[11] B. Philippe, W. Dawydoff, K.-J. Linow, Zeitschrift für Chemie 22 (1982) 113.

[12] W. Argüelles-Monal, M. Gárciga, C. Peniche-Covas, Study of the Stoichiometric Polyelectrolyte Complex between Chitosan and Carboxymethyl Cellulose, Polymer Bull. 23 (1990) 307-313.

[13] J. Laine, T. Lindström, T., The Colloid/Polyelectrolyte Titration Technique - a Review and an Appraisal of the Technique, Proc. EC/COST E14 Workshop: New Measurement Techniques for Monitoring White Water Chemistry in Papermaking, Lisbon, April 7, 2000.

[14] S. Dragan, M. Cristea, Polyelectrolyte Complexes IV. Interpolyelectrolyte Complexes between some Polycations with $\mathrm{N}, \mathrm{N}$-dimethyl-2hydroxyprolyleneammonium chloride units and Poly(sodium styrenesulfonate) in Dilute Aqueous Solution, Polymer 43 (1) (2002) 5562.

[15] H. Tanaka, Effects of Salts on Colloid Titration, Japan Tappi 37 (10) (1983) 939-948.

[16] V. A. Kabanov, A. B. Zezin, Soluble Interpolymeric Complexes as a new Class of Synthetic Polyelectrolytes, Pure Applied Chem. 56 (3) (1984) 343-354.

[17] J. Kötz, K.-J. Linow, B. Philipp, H. Dautzenberg, The Formation of WaterSoluble Polysalts. $4^{\text {th }}$ Comm.: Investigation of the Transition from a Soluble Symplex to Precipitation of a Polysalt, Acta Polymerica 37 (2) (1986) 108-112.

[18] P. Haronska, J. Kötz, B. Philipp, Interpretation of the Deviation of Symplex Stoichiometry from 1:1 Ratio, Acta Polymerica 40 (2) (1989) 110-112.

[19] J. Kötz, Phase Behavior of Polyanion-Polycation Aggregates and Possibilities of Utilization, Nordic Pulp Paper Res. J. 8 (1) (1993) 11-14. 
[20] J. Kekkonen, H. Lattu, P. Stenius, Adsorption Kinetics of Complexes formed by Oppositely Charged Polyelectrolytes, J. Colloid Interface Sci. 234 (2) (2001): 384-392.

[21] H. Tanaka, Determining Charge Demand of Suspensions using ChromoPDADMAC, Intl. Symp. Environ. Friendly Emerging Technol. for a Sustainable Pulp and Paper Industry, Y.-C. Su and E. I. C. Wang, eds., Taiwan Forestry Res. Inst., April 2000.

[22] J. Chen, M. A. Hubbe, J. A. Heitmann, Measurement of Colloidal Charge in the Paper Mill by Streaming Current, Proc. TAPPI Papermakers Conf., March 2001, CD doc.

[23] W. F. Gerdes, A New Instrument - The Streaming Current Detector, Proc. $12^{\text {th }}$ National ISA Analysis Instrumentation Symp., Houston, Texas, 11-13 May 1966, pp. 181-198.

[24] P. H. Cardwell, Adsorption Studies Using a Streaming Current Detector, J. Colloid Interface Sci. 22 (2) (1966) 430-437.

[25] S. K. Dentel, K. M. Kingery, Theoretical Principles of Streaming Current Detection, Water Sci. Tech. 21 (1989) 443-453.

[26] T. Ojala, Charge Measurements of Different Furnishes Using Polyelectrolyte Titration with a Streaming Current Detector, Proc. TAPPI Papermakers Conf., 1993, Atlanta, GA, pp. 613-626.

[27] M. A. Hubbe, Selecting and Interpreting Colloidal Charge Measurements, in Proc. Scientific \& Technical Advances in Wet End Chemistry, Barcelona, Spain, PIRA Intl., Leatherhead, 2000.

[28] P. A. Patton, D. T. Lee, Charge Analyses: Powerful Tools in Wet-End Optimization, TAPPI J. 76 (8) (1993) 107-115.

[29] L. Bley, Latest Experiences of On-Line Charge Measurements: A Process Control Concept - Optimized Runnability is Strongly Related to the Forces in the Wet End of a Paper Machine, Pulp Paper Mag. Canada 99 (5) (1998) 51-55.

[30] F. Wang, M. A. Hubbe, Development and evaluation of an automated streaming potential measurement device, Colloids Surf. A 194 (2001) 221232.

[31] W. Barron, B. S. Murray, P. J. Scales, T. W. Healy, D. R. Dixon, M. Pascoe, The streaming current detector: a comparison with conventional electrokinetic techniques, Colloids Surf. A 88 (1994) 129-139. 
[32] R. H. Müller, Zetapotential und Partikelladung in der Laborpraxis, Wissenschaftl. Verglagsges., Stuttgart, 1996.

[33] A. S. Michaels, Polyelectrolyte Complexes, Ind. Eng. Chem. 57 (10) (1965) 32-40.

[34] B. Philippe, H. Dautzenberg, K.-J. Linow, J. Kötz, W. Dawydoff, Polyelectrolyte Complexes - Recent Developments and Open Problems, Prog. Polymer. Sci. 14 (1) (1989) 91-172.

[35] A. Swerin, L. Ödberg, Some Aspects of Retention Aids, in The Fundamentals of Papermaking Materials, Vol. 1, C. F. Baker, Ed., PIRA, Leatherhead, UK, 1997, pages 265-351.

[36] S. Dragan, M. Cristea, Influence of Low-Molecular-Weight Salts on the Formation of Polyelectrolyte Complexes Based on Polycations with Quaternary Ammonium Salt Groups in the Main Chain and Poly(Sodium Acrylate), Eur. Poly. J. 37 (2001) 1571-1575.

[37] M. Mende, G. Petzold, G., H.-M. Buchhammer, Polyelectrolyte complex formation between poly(diallyldimethyl-ammonium chloride) and copolymers of acrylamide and sodium acrylate," Colloid Polym. Sci. 280 (4) (2002) 342-351.

[38] J. Kötz, B. Paulke, B. Philipp, P. Denkinger, W. Burchard, Polyanionpolycation-complex formation of charged microgels and latices with oppositely charged polyelectrolytes in solution, Acta Polymer 43 (4) (1992) 193-198.

[39] M. Möller, E. Nordmeier, E., Polyelectrolyte complexes formed by poly(diallyl- $N, N$-dimethylammoniumchloride) and oligo(dextransulphate), Eur. Polym. J. 38 (3) (2002) 445-450.

[40] L. Winter, L. Wågberg, L. Ödberg, T. Lindström, Polyelectrolytes adsorbed on the surface of cellulosic materials, J. Colloid Interface Sci. 111 (2) (1986) 537-543.

[41] M. D. Sikora, R. A. Stratton, Shear stability of flocculated colloids, Tappi 63 (11) (1981) 97-101.

[42] H. Tanaka, A. Swerin, L. Ödberg, Transfer of cationic retention aid from fibers to fine particles and cleavage of polymer chains under wet-end papermaking conditions, TAPPI J. 76 (5) (1993) 157-163. 
[43] J. Stamberg, H. Dautzenberg, F. Loth, M. Benes, and A. Kühn, D.D.R. Pat. 218,372, C08 B 15 06, Feb. 2, 1985.

[44] D. V. Pergushov, H.-M. Buchhammer, H.-M., K. Lunkwitz, Effect of LowMolecular-Weight Salt on Colloidal Dispersions of Interpolyelectrolyte Complexes, Colloid Polym. Sci. 277 (1999) 101-107.

[45] H. Dautzenberg, N. Karibyants, Polyelectrolyte complex formation in highly aggregating systems. Effect of salt: Response to subsequent addition of NaCl, Macromol. Chem. Phys. 200 (1999) 118-125.

[46] H.-M. Buchhammer, G. Petzold, K. Lunkwitz, Nanoparticles based on polyelectrolyte complexes: Effect of structure and net charge on the sorption capability for solved organic molecules, Colloid Polym. Sci. 278 (2000) 841-847.

[47] H. Tanaka, K. Tachiki, M. Sumimoto, Adsorption of cationic polymers onto bleached kraft pulp, Tappi 62 (1) (1979) 41-44.

[48] J. Laine, J. Buchert, L. Viikari, P. Stenius, Characterization of unbleached kraft pulps by enzymatic treatment, potentiometric titration and polyelectrolyte adsorption, Holzforschung 50 (3) (1996) 208-214.

[49] O. J. Rojas, M. Ernstsson, R. D. Neuman, P.M. Claesson, X-Ray Photoelectron Spectroscopy in the Study of Polyelectron Adsorption on Mica and Cellulose, J. Phys. Chem. B 104 (43) (2000) 10032-10042.

[50] M. A. Hubbe, T. L. Jackson, M. Zhang, Fiber surface saturation as a strategy to optimize dual-polymer dry strength treatment, TAPPI J., submitted for publication.

[51] S. T. Dubas, J. B. Schlenoff, Factors controlling the growth of polyelectrolyte multilayers, Macromolecules 32 (1999) 8153-8160.

[52] G. Decher, M. Eckle, J. Schmitt, B. Struth, Layer-by-layer assembled multicomposite films, Current Opinion in Colloid Interface Sci. 3 (1998) 3239.

[53] F. Caruso, H. Lichtenfeld, E. Donath, H. Möhwald, Investigation of electrostatic interactions in polyelectrolyte multilayer films: Binding of anionic fluorescent probes to layers assembled onto colloids, Macromolecules 32 (1999) 2317-2317.

[54] M. Beer, M. Schmidt, M. Muthukumar, The Electrostatic Expansion of Linear Polyelectrolytes: Effects of Gegenions, Co-ions, and Hydrophobicity, Macromolecules 30 (26) (1997) 8375-8385. 
[55] J. Yang, D. Sohn, N.-J. Kim, Conformations of Anionic and Cationic Polyelectrolytes in Various Salt Solutions, Polymer (Korea) 23 (5) (1999) 708-716.

[56] T. Lindström, L. Wågberg, Effects of $\mathrm{pH}$ and electrolyte concentration on the adsorption of cationic polyacrylamides on cellulose, Tappi J. 66 (6) (1983) 83-85.

[57] H. G. M. Van de Steeg, M. A. Cohen Stuart, A. de Keiser, B. H. Bijsterbosch, Polyelectrolyte adsorption: a subtle balance of forces, Langmuir 8 (1992) 2538-2546.

[58] O. J. Rojas, P. M. Claesson, D. Muller, R. D. Muller, The effect of salt concentration on adsorption of low-charge-density polyelectrolytes and interactions between polyelectrolyte-coated surfaces, J. Colloid Interface Sci. 205 (1998) 77-88.

[59] L. Ödberg, S. Sandberg, S. Welin-Klintström, H. Arwin, Thickness of Adsorbed Layers of High Molecular Weight Polyelectrolytes Studied by Ellipsometry, Langmuir 11 (7) (1995) 2621-2625.

[60] K. Vermohlen, H. Lewandowski, H. D. Narres, H. D., M. J. Schwuger, Adsorption of Polyelectrolytes onto Oxides - the Influence of lonic Strength, Molar Mass, and $\mathrm{Ca}^{2+}$ Ions, Colloids Surf. A 163 (1) (2000) 4553.

[61] S. Suty, B. Alince, T. G. M. van de Ven, Stability of ground and precipitated $\mathrm{CaCO} 3$ suspensions in the presence of polyethyleneimine and salt, J. Pulp Paper Sci. 22 (9) (1996) J321-J326.

[62] A. Swerin, L. Wågberg, Size-exclusion chromatography for characterization of cationic polyelectrolytes used in papermaking, Nordic Pulp and Paper Res. J. 9 (1) (1994) 18-25. 


\section{TABLES}

Table 1: The salt levels and corresponding conductivities.

\begin{tabular}{|l|r|}
\hline Salt level & Conductivity $(\mu \mathrm{S} / \mathrm{cm})$ \\
\hline Deionized water & $1.2-5.5^{*}$ \\
\hline $100 \mathrm{ppm} \mathrm{CaCl}_{2}$ & $275-280$ \\
\hline $100 \mathrm{ppm} \mathrm{CaCl}{ }_{2}$ and $100 \mathrm{ppm} \mathrm{NaCl}$ & $663-670$ \\
\hline $100 \mathrm{ppm} \mathrm{CaCl}_{2}$ and $0.1 \% \mathrm{NaCl}$ & $3550-3630$ \\
\hline $100 \mathrm{ppm} \mathrm{CaCl}_{2}$ and $1 \% \mathrm{NaCl}$ & $29500-29700$ \\
\hline
\end{tabular}

* Deionized water conductivity depended on how well the ionic exchanger was working on the day the titration was carried out.

Table 2: The general properties of polyelectrolytes

\begin{tabular}{|c|c|c|}
\hline $\begin{array}{c}\text { Type of } \\
\text { Polyelectrolyte }\end{array}$ & Supplier & Molecular Mass \\
\hline poly-DADMAC & Ciba Spec. Chem. & $1900 \mathrm{k}$ Dalton \\
\hline poly-DADMAC & Aldrich Co. & $400-500 \mathrm{k}$ Dalton \\
\hline poly-DADMAC & Aldrich Co. & $100-200 \mathrm{k}$ Dalton \\
\hline poly-DADMAC & Ciba Spec. Chem. & $15 \mathrm{k}$ Dalton ${ }^{*}$ \\
\hline PVSK & Aldrich Co. & $170 \mathrm{k}$ Dalton \\
\hline
\end{tabular}

${ }^{*}$ calculated from intrinsic viscosity (62)

Table 3: contact angle for PTFE tape before and after adsorption of polyDADMAC.

\begin{tabular}{|l|l|l|l|}
\hline & \multicolumn{3}{|c|}{ Contact Angle of Water on PTFE } \\
\hline $\begin{array}{l}\text { Conductivity } \\
(\mu \mathrm{S} / \mathrm{cm})\end{array}$ & Before adsorption & After adsorption & $\begin{array}{l}\text { Average change } \\
\text { in contact angle }\end{array}$ \\
\hline 278 & $112.5^{\circ} \pm 2.2^{\circ}$ & $106.3^{\circ} \pm 2.6^{\circ}$ & -6.2 \\
\hline 667 & $112.0^{\circ} \pm 2.2^{\circ}$ & $106.6^{\circ} \pm 2.3^{\circ}$ & -5.4 \\
\hline 3550 & $115.1^{\circ} \pm 1.6^{\circ}$ & $115.6^{\circ} \pm 1.8^{\circ}$ & +0.5 \\
\hline 29500 & $115.6^{\circ} \pm 1.8^{\circ}$ & $115.3^{\circ} \pm 1.6^{\circ}$ & -0.3 \\
\hline
\end{tabular}

Table 4: Contact angle for PTFE tape before and after adsorption of PVSK.

\begin{tabular}{|l|l|l|l|}
\hline & \multicolumn{3}{|c|}{ Contact Angle of Water on PTFE } \\
\hline $\begin{array}{l}\text { Conductivity } \\
(\mu \mathrm{S} / \mathrm{cm})\end{array}$ & Before adsorption & After adsorption & $\begin{array}{l}\text { Average change } \\
\text { in contact angle }\end{array}$ \\
\hline 278 & $114.0^{\circ} \pm 2.0^{\circ}$ & $109.1^{\circ} \pm 2.7^{\circ}$ & -4.9 \\
\hline 667 & $115.6^{\circ} \pm 1.6^{\circ}$ & $112.0^{\circ} \pm 1.6^{\circ}$ & -3.6 \\
\hline 3550 & $115.1^{\circ} \pm 1.6^{\circ}$ & $113.8^{\circ} \pm 1.6^{\circ}$ & -1.3 \\
\hline 29500 & $115.6^{\circ} \pm 1.8^{\circ}$ & $114.8^{\circ} \pm 2.7^{\circ}$ & -0.8 \\
\hline
\end{tabular}


Table 5. Ratio of anionic to cationic polyelectrolyte groups (-/+) at the point of rapid turbidity rise when titrating poly-DADMAC solutions of different molecular mass with PVSK.

\begin{tabular}{|l|l|l|l|}
\hline \multicolumn{5}{|l|}{} \\
\hline Poly-DADMAC mass & Low & $\begin{array}{l}\text { Medium (400- } \\
500 \mathrm{k} \text { Daltons })\end{array}$ & $\begin{array}{l}\text { High (1900 k } \\
\text { Daltons })\end{array}$ \\
\hline Hard water $(100 \mathrm{ppm} \mathrm{CaCl} 2)$ & 0.865 & 0.948 & 1.030 \\
\hline Hard $+100 \mathrm{ppm} \mathrm{NaCl}$ & 0.783 & 0.948 & 1.030 \\
\hline Hard $+0.1 \% \mathrm{NaCl}$ & 0.330 & 0.783 & 0.947 \\
\hline Hard $+1.0 \% \mathrm{NaCl}$ & 0.288 & 0.494 & 0.660 \\
\hline
\end{tabular}

\section{FIGURE CAPTIONS}

Fig. 1. Streaming current signal as a function of the stoichiometric ratio between poly-DADMAC (titrant) and polyvinylsulfate (present initially) at different $\mathrm{NaCl}$ levels to adjust the initial electrical conductivity

Fig. 2. "Entrapment" model in which the addition of titrant is assumed to cause segments of an oppositely charged polyelectrolyte to become isolated, protected from further complexation or equilibration

Fig. 3. "Surface excess" model in which polyelectrolyte complexes in the solution phase are assumed to have a near-neutral core and loops and tails of the titrant (second additive) extending from their surfaces

Fig. 4. Stoichiometric ratio at the endpoint of SC tests in which PVSK titrant was added to dilute solutions of poly-DADMAC in the presence of various salt concentrations. The unfilled and filled bars correspond to replicate tests.

Fig. 5. Results from confirmatory experiments with lower-mass poly-DADMAC, but otherwise identical to that corresponding to Fig. 4

Fig. 6. Stoichiometric ratio at the endpoint of SC tests in which poly-DADMAC titrant was added to dilute solutions of PVSK in the presence of various salt concentrations

Fig. 7. Results of tests with a different streaming current device (see Experimental), but carried out in the same direction as in Fig. 5.

Fig. 8. Effect of salts (100 ppm $\mathrm{CaCl}_{2}$, then increasing $\left.\mathrm{NaCl}\right)$ on $\mathrm{SC}$ output in the absence of polyelectrolytes

Fig. 9. Amount of poly-DADMAC needed to reach zero SC signal in the absence of poly-acid at the same salt conditions as in Fig. 8 
Fig. 10. Initial SC signal in the presence of $6.0 \mu \mathrm{eq} / \mathrm{L}$ poly-DADMAC (upper curve) or 4.8-5.4 $\mu \mathrm{eq} / \mathrm{L}$ PVSK (lower curve) at different salt levels corresponding to Figs. 5-9

Fig. 11. Concentrations of poly-DADMAC in the SC endpoint mixture at different initial concentrations of PVSK in the starting solution

Fig. 12. Concentrations of PVSK in the SC endpoint mixture at different initial concentrations of poly-DADMAC in the starting solution

Fig. 13. Turbidity as a function of the ratio of charged groups during addition of PVSK titrant to a poly-DADMAC solution at various salt levels

Fig. 14. Results of identical experiment to Fig. 13, except that the salt addition was $100 \mathrm{ppm} \mathrm{CaCl}_{2}$ and $1 \% \mathrm{NaCl}$.

Fig. 15. Turbidity as a function of the ratio of charged groups during addition of poly-DADMAC titrant to a PVSK solution at various salt levels. Empty and filled symbols represent replicate series of tests.

Fig. 16. Results of identical experiment to Fig. 15, except at the highest level of salt addition (100 ppm $\mathrm{CaCl}_{2}$ and $\left.1 \% \mathrm{NaCl}\right)$. Empty and filled symbols represent replicate series of tests. 


\section{FIGURES}

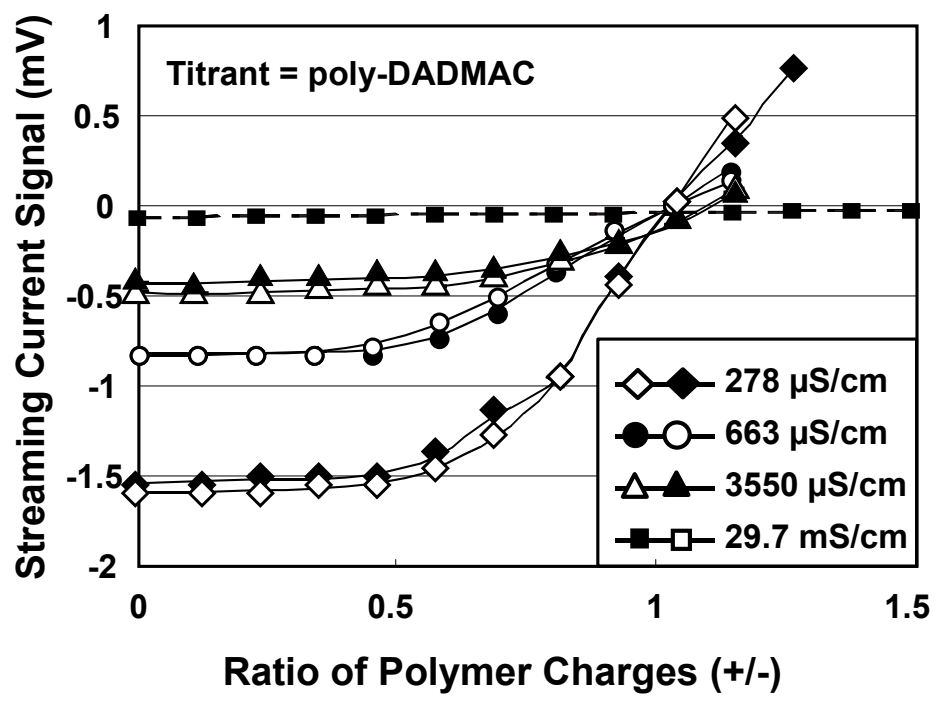

Fig. 1. Streaming current signal as a function of the stoichiometric ratio between poly-DADMAC (titrant) and polyvinylsulfate (present initially) at different $\mathrm{NaCl}$ levels to adjust the initial electrical conductivity

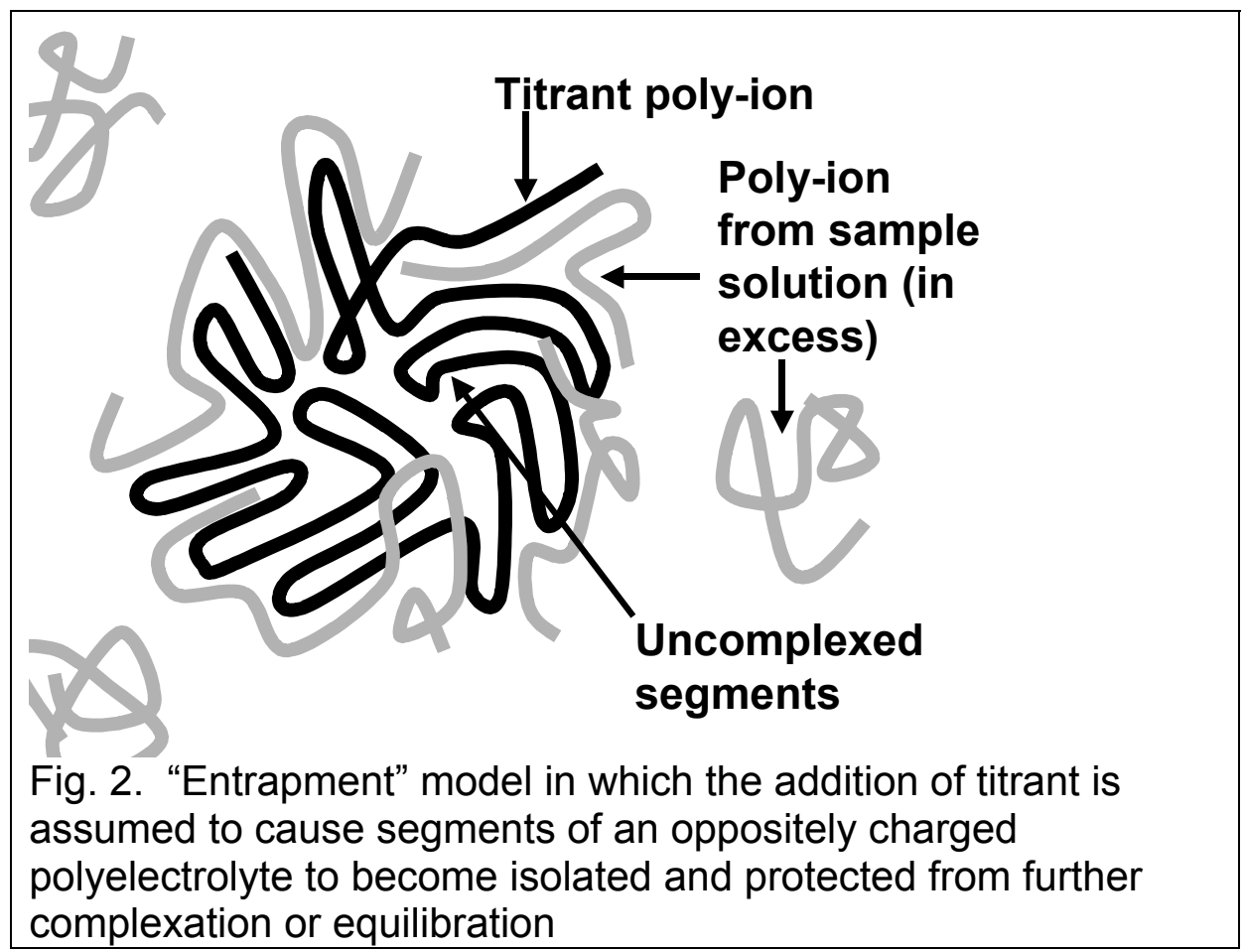




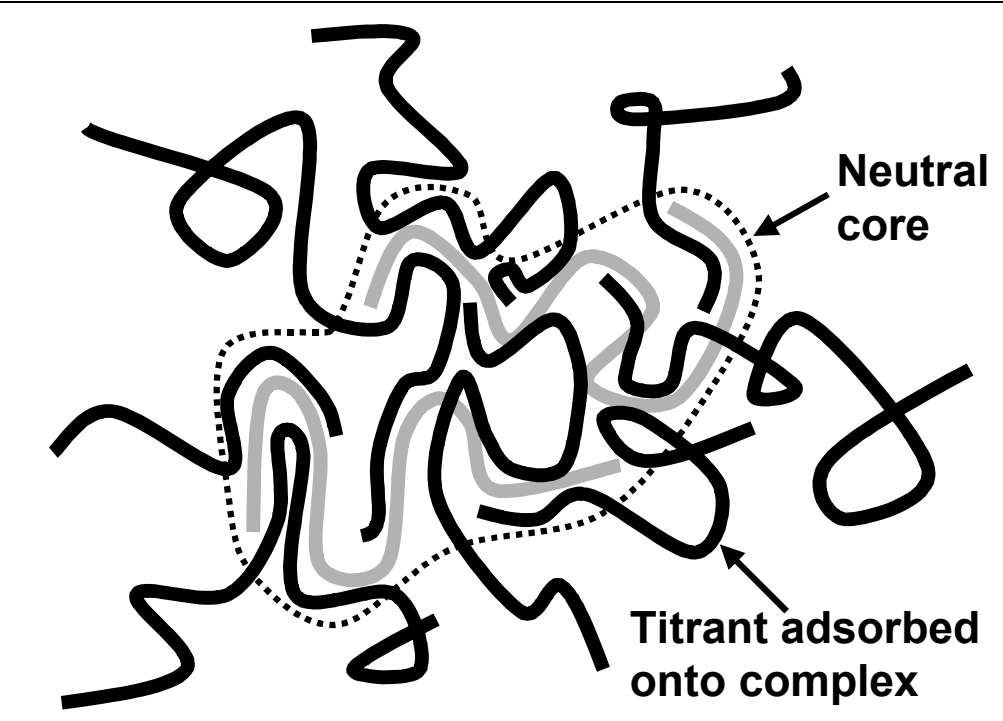

Fig. 3. "Surface excess" model in which polyelectrolyte complexes in the solution phase are assumed to have a near-neutral core and loops and tails of the titrant (second additive) extending from their surfaces

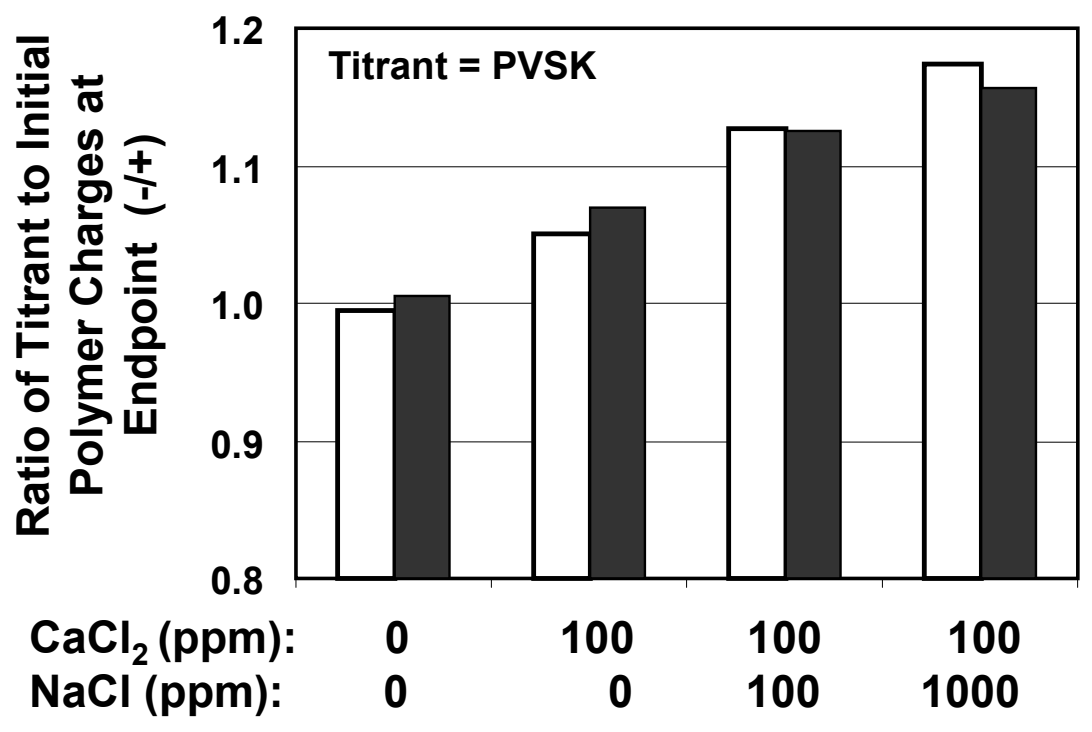

Fig. 4. Stoichiometric ratio at the endpoint of SC tests in which PVSK titrant was added to dilute solutions of poly-DADMAC in the presence of various salt concentrations. The unfilled and filled bars correspond to replicate tests. 


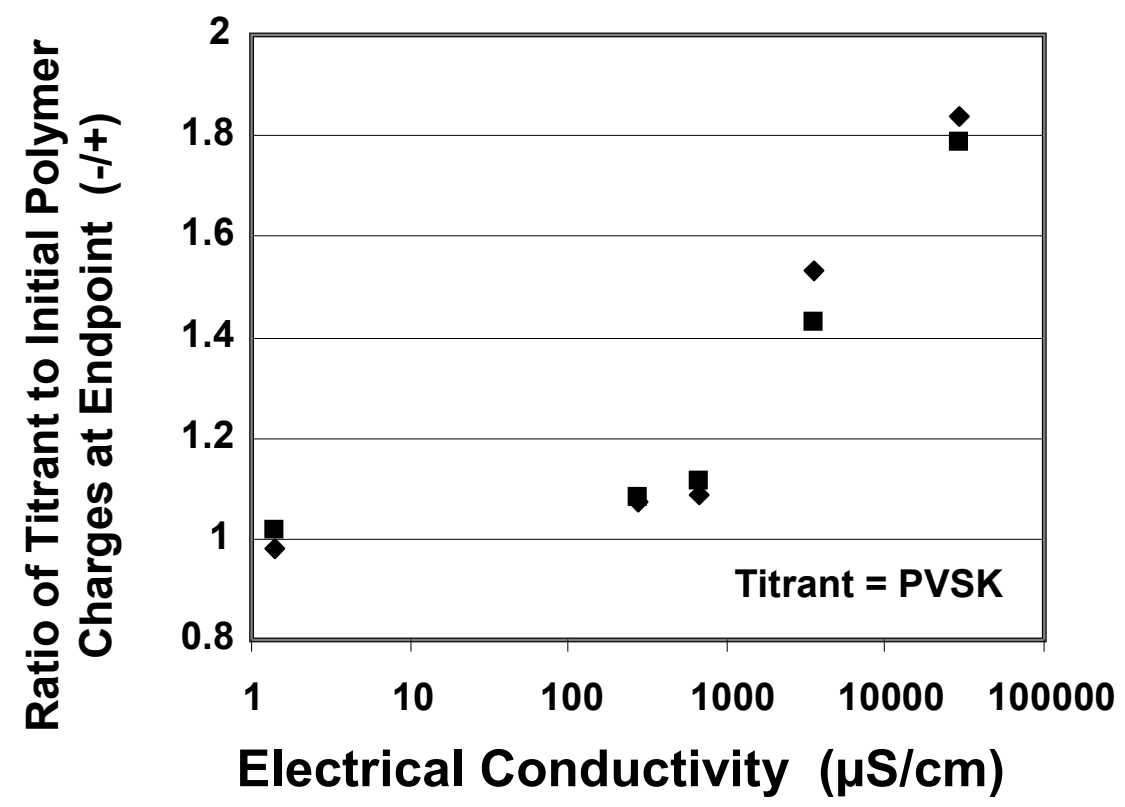

Fig. 5. Results from confirming experiments with lower-mass polyDADMAC, but otherwise identical to that corresponding to Fig. 4

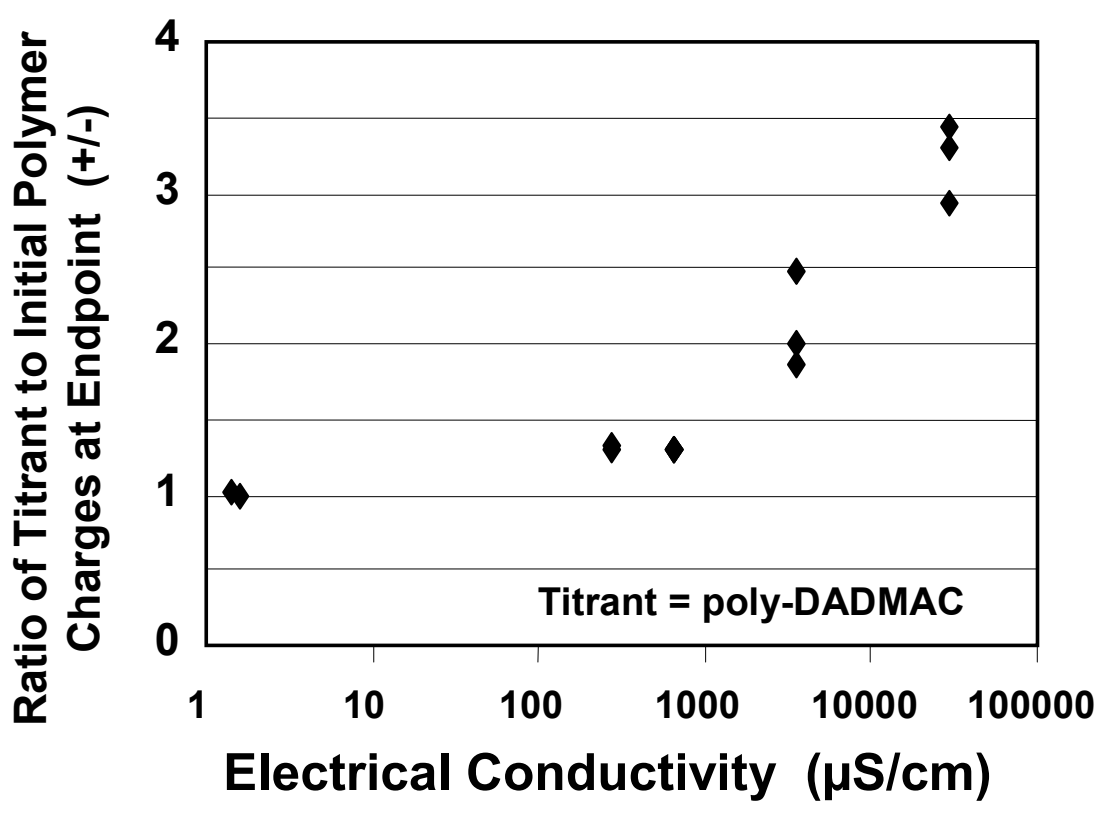

Fig. 6. Stoichiometric ratio at the endpoint of SC tests in which polyDADMAC titrant was added to dilute solutions of PVSK in the presence of various salt concentrations 


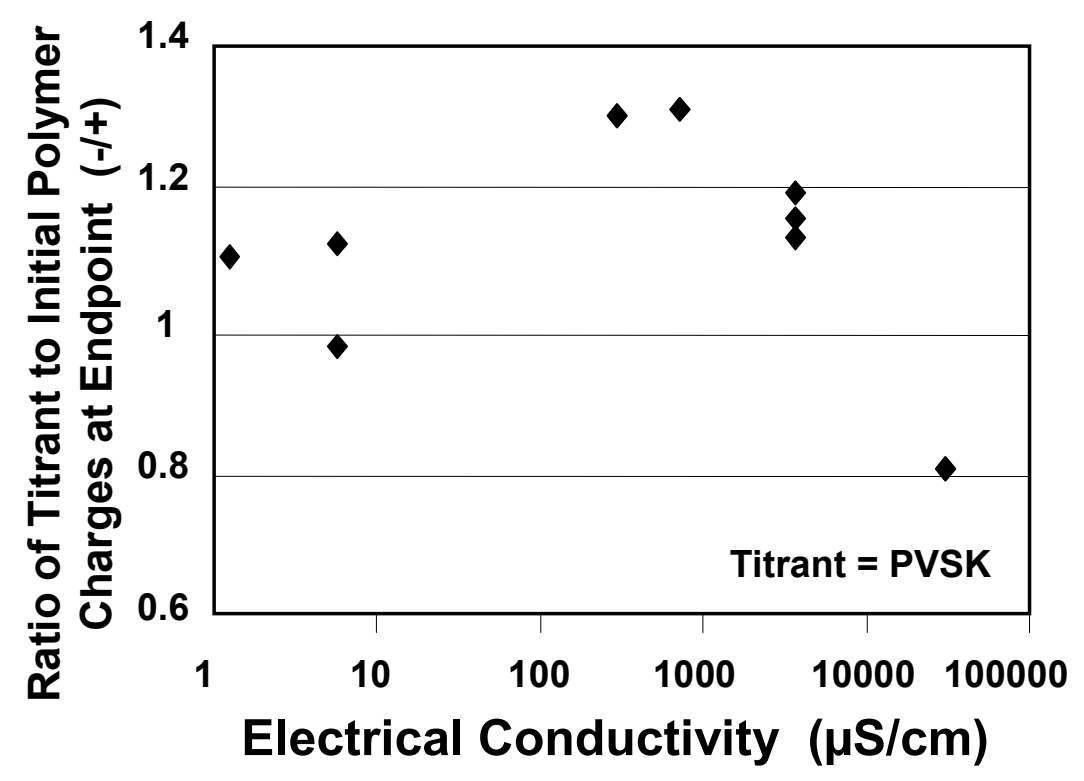

Fig. 7. Results of tests with a different streaming current device (see Experimental), but carried out in the same direction as in Fig. 5.

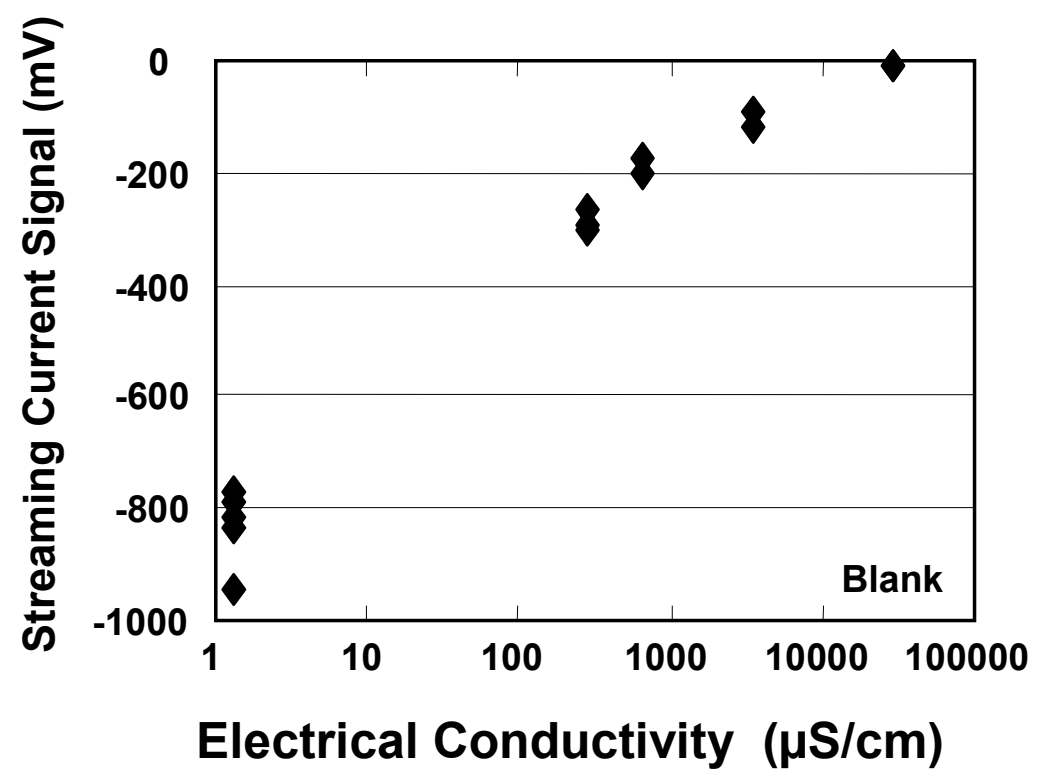

Fig. 8. Effect of salts ( $100 \mathrm{ppm} \mathrm{CaCl}_{2}$, then increasing $\left.\mathrm{NaCl}\right)$ on $\mathrm{SC}$ output in the absence of polyelectrolytes 


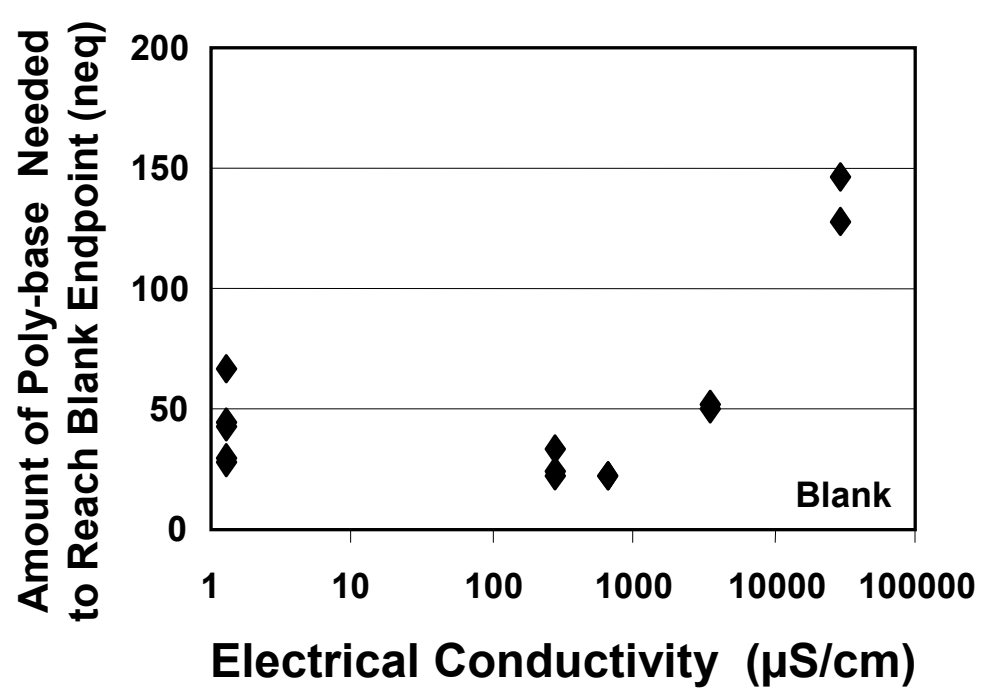

Fig. 9. Amount of poly-DADMAC needed to reach zero SC signal in the absence of poly-acid at the same salt conditions as in Fig. 8

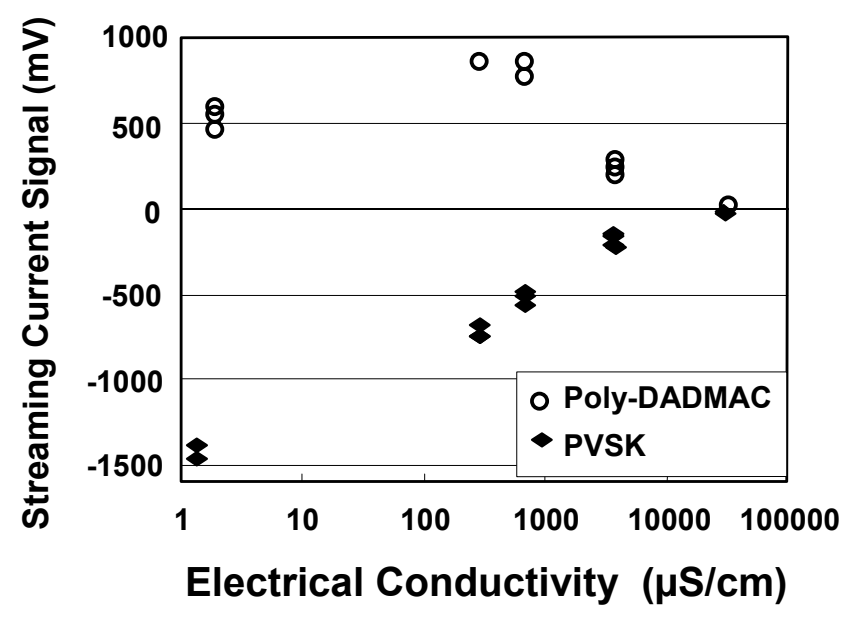

Fig. 10. Initial SC signal in the presence of $6.0 \mu \mathrm{eq} / \mathrm{L}$ poly-DADMAC (upper curve) or 4.8-5.4 $\mu \mathrm{eq} / \mathrm{L}$ PVSK (lower curve) at different salt levels corresponding to Figs. 5-9 


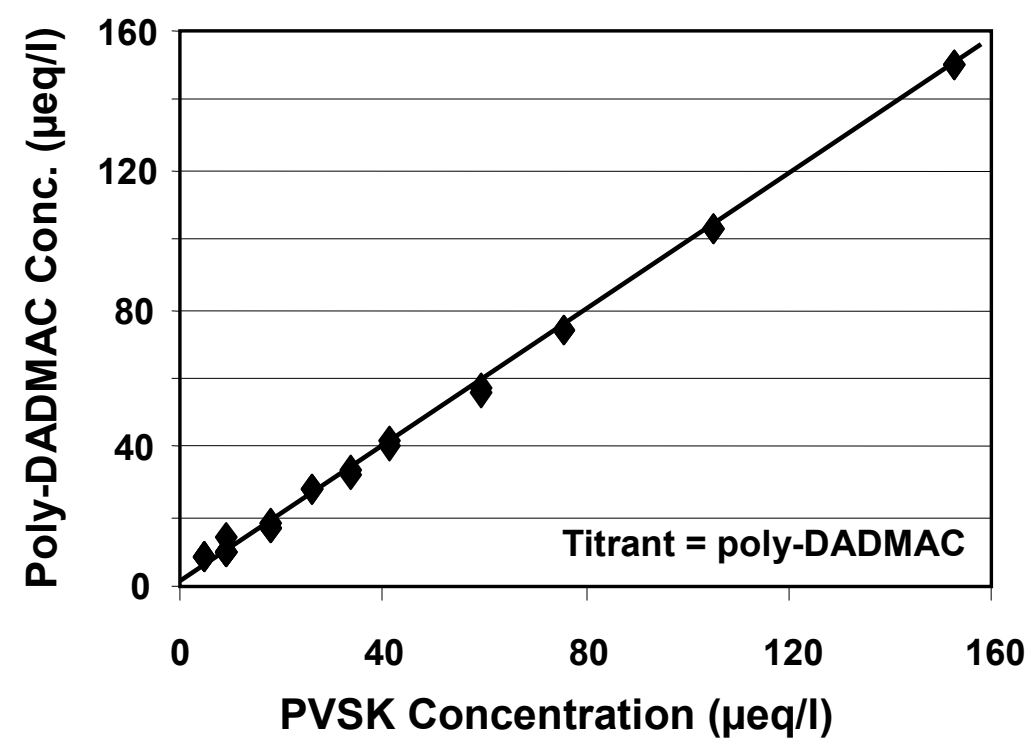

Fig. 11. Concentrations of poly-DADMAC in the SC endpoint mixture at different initial concentrations of PVSK in the starting solution

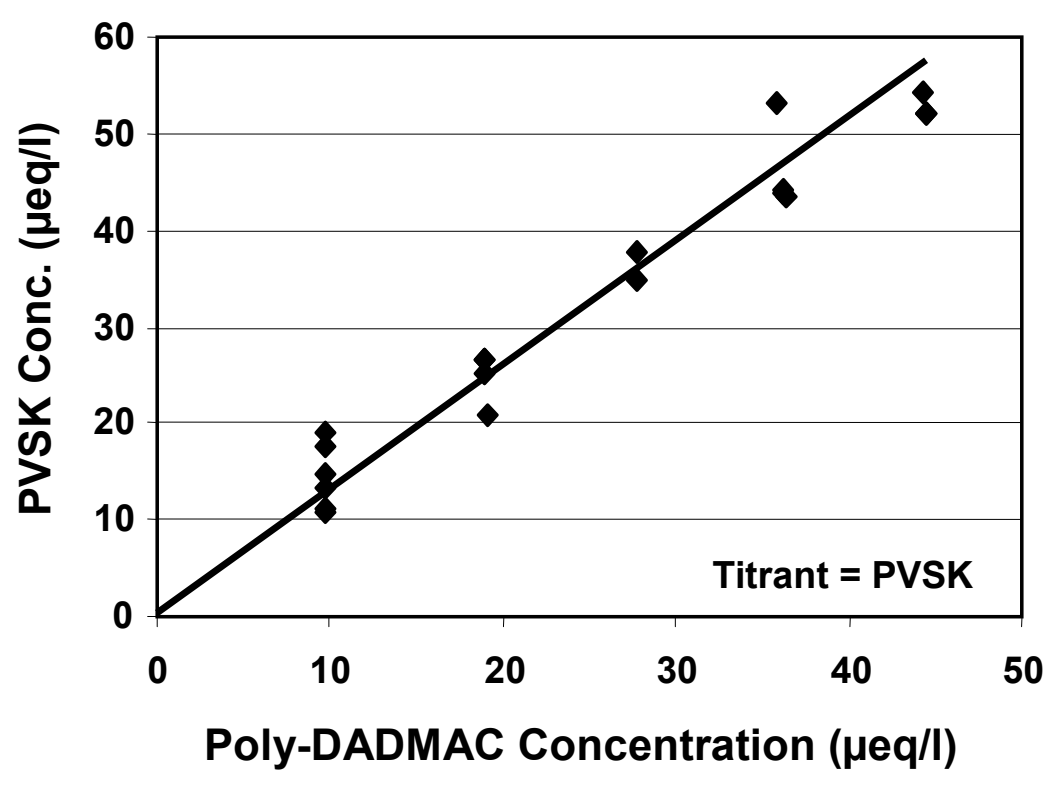

Fig. 12. Concentrations of PVSK in the SC endpoint mixture at different initial concentrations of poly-DADMAC in the starting solution 


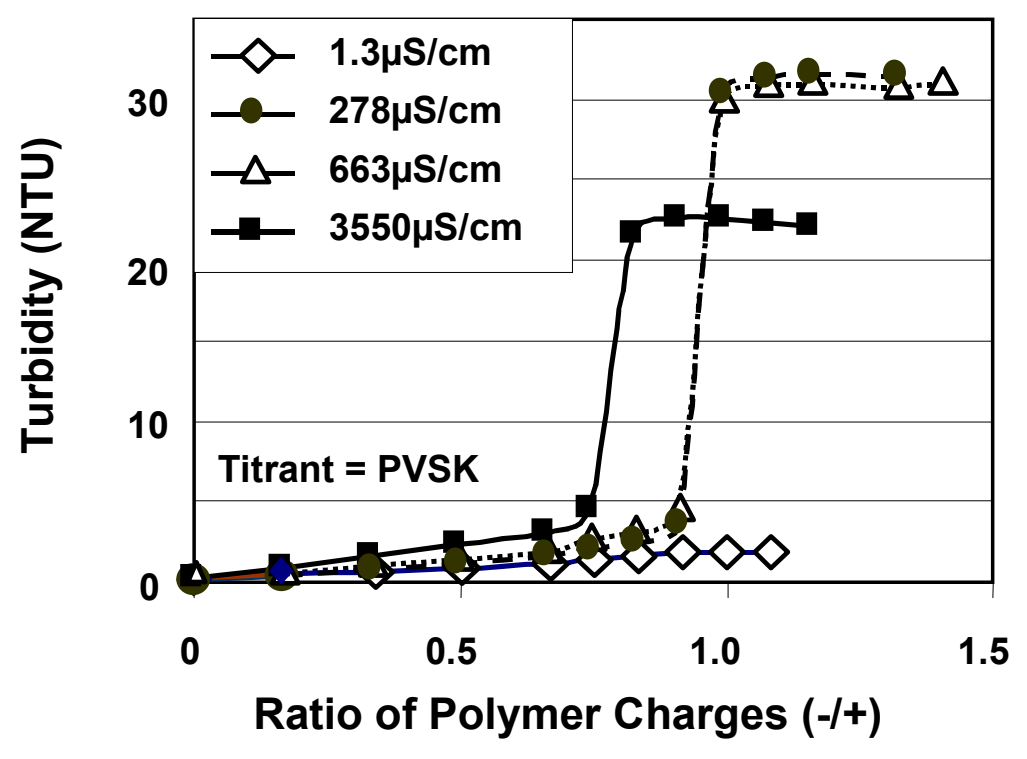

Fig. 13. Turbidity as a function of the ratio of charged groups during addition of PVSK titrant to a poly-DADMAC solution at various salt levels

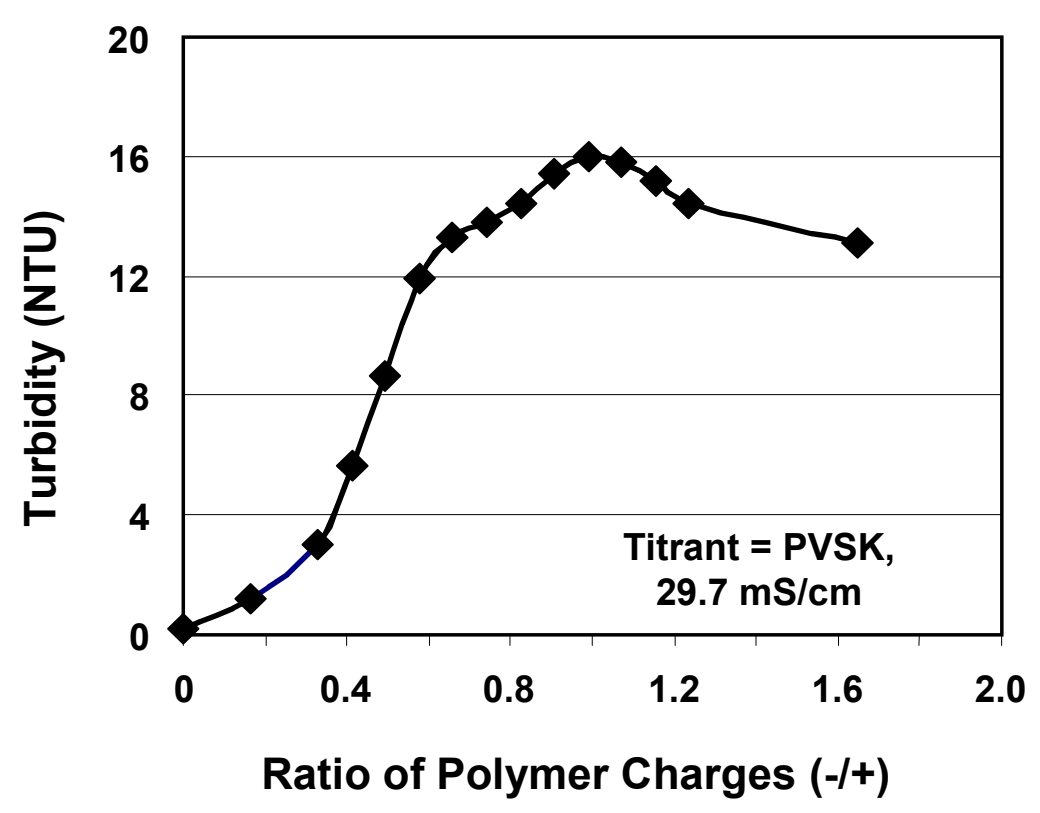

Fig. 14. Results of identical experiment to Fig. 13, except that the salt addition was $100 \mathrm{ppm} \mathrm{CaCl}_{2}$ and $1 \% \mathrm{NaCl}$. 


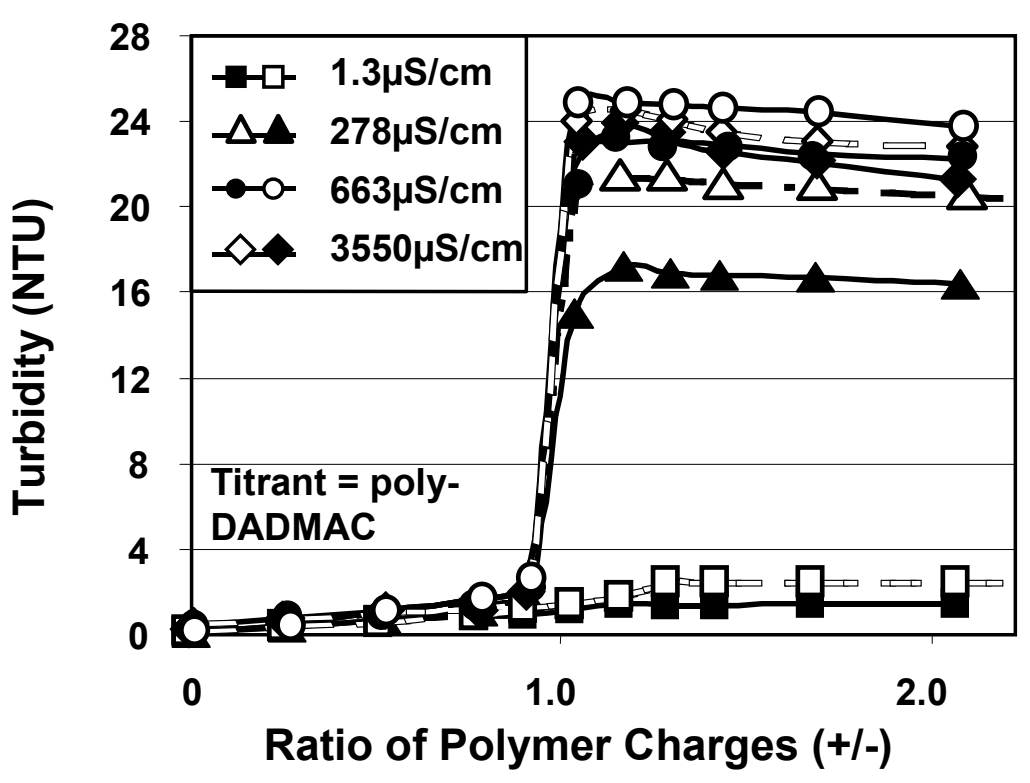

Fig. 15. Turbidity as a function of the ratio of charged groups during addition of poly-DADMAC titrant to a PVSK solution at various salt levels. Empty and filled symbols represent replicate series of tests.

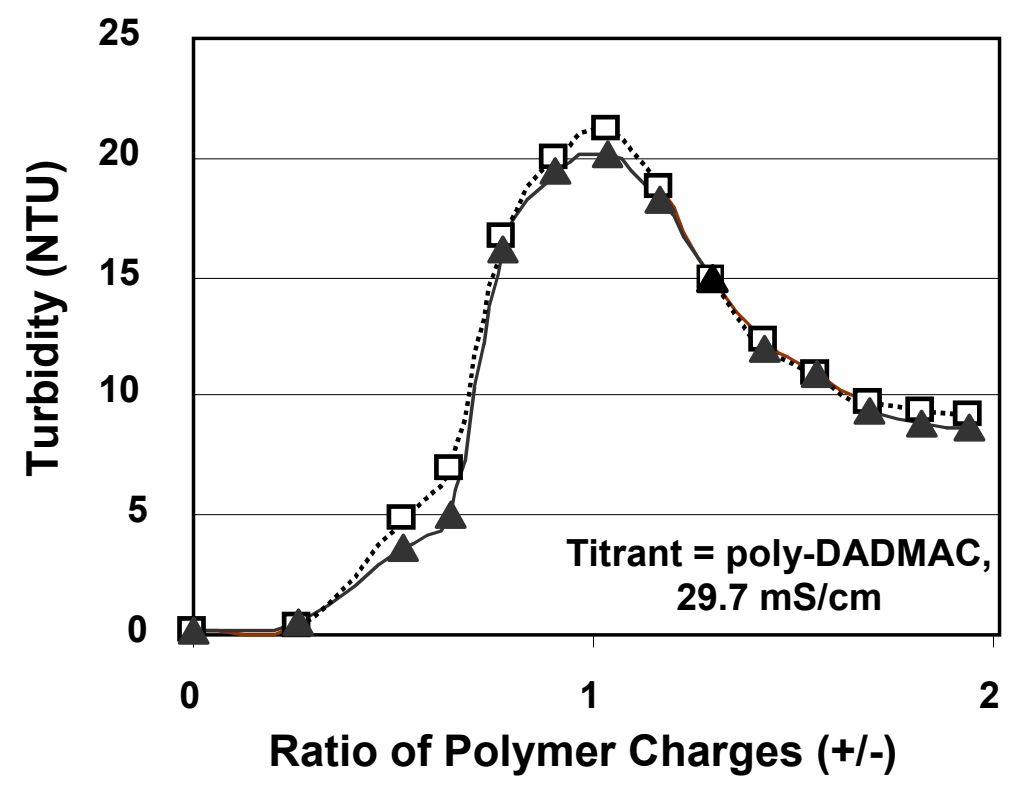

Fig. 16. Results of identical experiment to Fig. 15, except at the highest level of salt addition (100 ppm $\mathrm{CaCl}_{2}$ and $1 \% \mathrm{NaCl}$ ). Empty and filled symbols represent replicate series of tests. 